scientific community that high-dose testing does not produce false positive results, and that this is necessary to reduce the insensitivity of carcinogenicity tests, reflecting the small number of animals tested compared with large human populations at presumptive risk ${ }^{6}$. It is also well recognized that carcinogenicity testing in excess of maximally tolerated doses (MTD) can produce false negatives due to competing toxicity.

Peto's charge of selective omission of the saccharin data is not his only misrepresentation. After his circulation of drafts of his review to various US experts in the autumn of 1979, Schneiderman, then Associate Director for Science Policy of the National Cancer Institute (NCI) and co-author of the government report on the importance of occupational carcinogens ${ }^{7}$, explained in a letter to Peto that breast cancer correlates as well with Gross National Product as fat, that occupation had been ignored in studies exclusively associating lung cancer with smoking, that there have been major recent increases in lung cancer among non-smokers and that there have been "big and frightening" recent increases in cancer incidence which cannot be accounted for by smoking or other lifestyle factors.

Similarly, Upton, then Director of NCI and a co-author of the report ${ }^{7}$, challenged the erroneous charge that a " $4-5$ " multiplication factor was used to inflate the 1978 government estimates of cancer anticipated from occupational exposures. ". . . This simply is not true ..."

Repeatedly, Peto dismisses as personal views statements in The Politics of Cancer to which he takes exception, rather than recognizing that they are based on fully referenced primary sources and without attempting to challenge these sources directly. For instance, he disparages the conclusion "that the cure rates for major cancers have not been improving much over recent years", without noting that this reflects cited $\mathrm{NCI}$ data. Peto refers to the "claims that cancer costs the US economy over $\$ 25$ billion per year" without recognizing that such figures are derived from NCI sources. Similarly, Peto criticizes as "misleading or unbalanced" references to the term "medical-industrial complex" without attribution to its source, referenced and identified in the text (p.77), as the caption of an editorial in The Lancet ${ }^{8}$.

Peto charges that the book denigrates the value of short-term carcinogenicity tests, which he asserts is a "most inexplicable error of scientific judgement". While problems of such tests, particularly the limited associations between carcinogenicity and Ames test data for compounds from a wide range of structural classes ${ }^{9,10}$ are recognized, the book concludes (p.68) that there is a "range of useful applications" for these tests, particularly when incorporated into battery protocols.

Peto accepts that industries "delay or obstruct any hygienic measures which will cost money, ... . (and) that the scientific literature is not immune from distortion by financial interests". Peto apparently also accepts the wide range of case studies in The Politics of Cancer, which document a common pattern of constraints, including manipulation, distortion and destruction, in health, safety and economic data generated or interpreted by industry and its consultants. Yet he seems willing to accept studies sponsored or endorsed by industry as authority for the nearly exclusive lifestyle theory of cancer causation. Moreover, he is opposed to further regulatory controls on grounds of costs, professed "inactive conservatism", and because "for most toxic chemicals, we now have both qualitative and quantitative uncertainty about the health benefits of restriction". This seems a questionable basis for prudent public health policy.

School of Public Health,

University of Illinois at the

Medical Center, Chicago, Illinois

1. Epstein, S.S The Politics of Cancer (Sierra Club Books, San Francisco 1978, revised and expanded in Anchor Doubleday, New York, 1979, to which quotations refer). 2. Peto, R. Nature 284, 297-300 (1980).

3. Cancer Testing Technology and Saccharin U.S. Congress, Washington, D.C., June 7, 1977

4. Wolfe, S.M. Johnson, A. Public Citizens Health Research Group, Testimony Before Subcommittee on Health, House Commerce Committee Hearings on Saccharin. House Commerce

. Reuber, M.D. Envir. Hith Perspect. 25, 173 (1978)

6. Report 10 the Surgeon General, USPHS, Evaluation of Environmental Carcinogens (Ad Hoc Committee on the Evaluation of Low Levels of Environmental Chemical Carcinogens, April 22, 1970).

7. Bridbord, K. et al. Estimates of the Fraction of Cancer in the United States Related to Occupational Factors (NCI, National Institute of Environmental Health Sciences, and National Institute for Occupational Safety and Health, 15 September, 1978)

. Lancet ii, 1380 (1973)

. Rinkus, S.J.\& L eyalor, M.S. Cancer Res. 39, 3289 (1979).

10. International Program for the Evaluation of Short Term Tests for Carcinogenicity National Toxicology Program. Dept of Health and Human Services, April, 1980.

The article "Fallacies of lifestyle cancer

theories" by S.S. Epstein and J.B. Swartz

begins on page 127 of this issue.

\section{Spanish science}

SIR - The publication (Nature 23 October 1980, p.674) of the Manifesto on the status of science in Spain issued by leading academics and scientists of universities and research institutes is a major event. I would like to make a few comments from the viewpoint of a scientist who has been working closely for over ten years with colleagues at Spanish universities.

This is a time of great expectations both nationally and internationally for Spanish science and engineering. Democratic changes and heightened national expectations have opened the door for a major strengthening of scientific, engineering and technological work. The largely dormant past in universities and the undeveloped governmental infrastructure for science are giving way to a healthy stirring throughout the whole system. A recent visit to Madrid confirms a vigorous self-examination of the structure of research and teaching with significant organizational changes proposed.

There is, of course, no unique set of circumstances that will guarantec motivation of faculty and students, but there generally appear 10 be three essential elements. Scientists must be assured of government respect for scientific work without political interference; there must be reasonable financial support and job opportunities for researchers and graduate students; and there must be adequate and respected links between government, universities and public and private research institutions. Only the first element is now firmly in place. Difficulty in providing the second element is not unique to Spain, but occurs in many industrial countries of moderate size where the number of research positions is limited. At the moment, for this reason, some of the best Spanish science and engineering graduates see their future abroad.
Academics might themselves develop research institutes within the universities directed to national needs such as high technology, engineering services, mitigation of earthquake and other natural hazards, and agricultural improvements. Although such efforts are exhausting and time-consuming, entrepreneurship to draw in industry, provincial governments and private funds is an essential part of scientific vigour. The Manifesto appears to address largely the central government. No doubt, realistically at this stage, the major funding for research must come from Madrid, but, in the long run, a diversity of support would appear to be the most fruitful.

The third element should be easier to achieve since it does not in itself entail much expenditure. The need to examine critically scientific goals and infrastructure related to national needs has in other countries led to the establishment of something like a Royal Commission with independent powers to probe, report and recommend. Strengthening and linking government institutes undertaking research, similar to the highly effective scientific and industrial research organizations of Australia, New Zealand and elsewhere might be considered. There appears to be a need to integrate government scientific institutes more closely with universities, given the new social climate in Spain in which protection from debilitating political agitation is not required.

From my own experience, it is crucial for scientists and engineers in Spain to organize themselves systematically so that their professional societies and academies are representative and respected. The work of such associations can clearly demonstrate to the body politic (of all parties) that among the many competing interests in a modern state, science should have a high priority on both economic and cultural grounds. Rather than an emphasis on "rights", continual demonstration is needed of the way that scientific enquiry really maintains itself in a free society. Again, from my own experience, it is important to cultivate those members of the Cortes who are scientists, engineers, technologists and economists. If they are to accept the responsibility of speaking for the Spanish scientific community they must have the necessary contacts and realistic proposals that can be argued effectively.

Finally, as a sympathetic outsider, I am struck by the role that Spanish science and technology might play in the developing world. Much of Central and South America lies open, one would suppose, to the establishment of close ties with Spanish scientists and institutions. The value of common language and other heritages canno be overemphasized. Although some cultural and scientific ties have been forged, there are exciting possibilities for an expansion of teaching, scientific exchanges, bilateral scientific and technological agreements.

Through such channels, the idealism and abilities of many Spanish science graduates could find a natural place that serves not only national self-interest but also the global responsibility of all scientists. Might we not look forward to a vigorous Spanish science that belongs not only to Europe but also to the Americas? Part of the answer lies in the force of the Manifesto itself.

Bruce A. Bolt

University of California,

Berkeley, California 